\title{
Hydrogeological and hydrogeochemical characterization of a karstic mountain region
}

\author{
Celalettin Simsek · Alper Elci · Orhan Gunduz • \\ Burhan Erdogan
}

Published online: 8 August 2007

(C) Springer-Verlag 2007

\section{Erratum to: Environ Geol \\ DOI 10.1007/s00254-007-0817-4}

The original article was published with an incorrect excess deuterium $\left(\delta^{2} \mathrm{H}\right)$ symbol $(\%)$. The correct symbol is $(\%)$.

In the Table 1, the excess deuterium values are incorrect and each value on the list needs to be increased by 10 (in column 11 of the table as shown below) and the corresponding Fig. 6 is corrected and given below.

The online version of the original article can be found under doi:10.1007/s00254-007-0817-4.

\section{Simsek ( $\square)$}

Department of Drilling, Torbali Technical Vocational

School of Higher Education,

Dokuz Eylul University,

35860 Torbali-Izmir, Turkey

e-mail: celalettin@deu.edu.tr

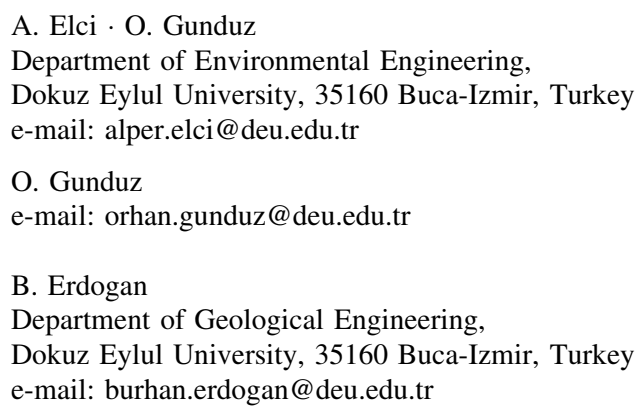


Table 1 Isotopic composition for some sampled springs

\begin{tabular}{llllllllllll}
\hline $\begin{array}{l}\text { Spring } \\
\text { no. }\end{array}$ & $X(\mathrm{~m})$ & $Y(\mathrm{~m})$ & $\begin{array}{l}Z \\
(\mathrm{~m})\end{array}$ & $\begin{array}{l}\text { Discharge } \\
\text { rate }(\mathrm{L} / \mathrm{s})\end{array}$ & $T\left({ }^{\circ} \mathrm{C}\right)$ & $\mathrm{pH}(-)$ & $\mathrm{EC}(\mu \mathrm{S} / \mathrm{cm})$ & $\begin{array}{l}\Delta^{18} \mathrm{O} \\
(\%)\end{array}$ & $\begin{array}{l}\delta^{2} \mathrm{H} \\
(\%)\end{array}$ & $\begin{array}{l}\delta^{2} \mathrm{H} \text { excess } \\
(\%)\end{array}$ & $\begin{array}{l}\text { Tritium } \\
(\mathrm{TU})\end{array}$ \\
\hline P-4 & $526,781.8$ & $4,251,761.3$ & 369 & NA & 12.8 & 7.76 & 351 & -6.36 & -34.2 & 16.67 \\
P-6 & $537,800.4$ & $4,249,025.0$ & 273 & NA & 16.6 & 7.33 & 467 & -6.62 & -35.7 & 17.23 \\
P-7 & $534,532.2$ & $4,251,955.4$ & 650 & NA & 12.0 & 7.60 & 328 & -7.15 & -39.8 & 17.41 \\
P-9 & $533,970.9$ & $4,249,150.5$ & 861 & NA & 10.8 & 7.80 & 237 & -7.14 & -39.9 & 17.22 \\
P-10 & $533,402.1$ & $4,249,728.4$ & 954 & NA & 11.2 & 7.87 & 215 & -7.47 & -42.5 & 17.29 \\
P-14 & $536,854.5$ & $4,244,450.9$ & 320 & 256.00 & 16.3 & 7.10 & 612 & -6.92 & -38.1 & 17.32 \\
P-15 & $533,778.2$ & $4,243,949.5$ & 421 & 185.00 & 14.1 & 7.18 & 371 & -7.11 & -38.4 & 18.49 \\
P-18 & $528,073.8$ & $4,241,121.9$ & 361 & 0.67 & 14.7 & 6.93 & 586 & -5.82 & -32.0 & 14.53 \\
P-22 & $527,515.4$ & $4,245,869.2$ & 619 & NA & 11.9 & 7.74 & 258 & -7.47 & -41.8 & 17.92 \\
P-27 & $523,314.6$ & $4,248,350.3$ & 279 & NA & 13.4 & 7.25 & 516 & -5.95 & -33.6 & 13.98 \\
P-29 & $521,466.6$ & $4,250,378.3$ & 144 & 0.07 & 15.4 & 6.62 & 891 & -5.49 & -29.8 & 14.10 \\
P-30 & $530,990.5$ & $4,244,508.0$ & 1027 & 0.49 & 12.4 & 7.28 & 511 & -6.79 & -35.5 & 18.87 \\
P-31 & $532,945.9$ & $4,246,821.9$ & 1116 & 1.25 & 10.7 & 7.93 & 212 & -7.60 & -42.5 & 18.30 \\
P-33 & $522,115.8$ & $4,234,555.4$ & 138 & NA & 17.3 & 6.59 & 497 & -6.84 & -38.5 & 16.18 \\
P-34 & $524,717.0$ & $4,233,647.5$ & 103 & 877.50 & 17.3 & 7.13 & 574 & -6.73 & -37.3 & 16.53
\end{tabular}

NA Not available (could not be measured)

\section{$\delta^{2} \mathrm{H}$ excess (\%o)}

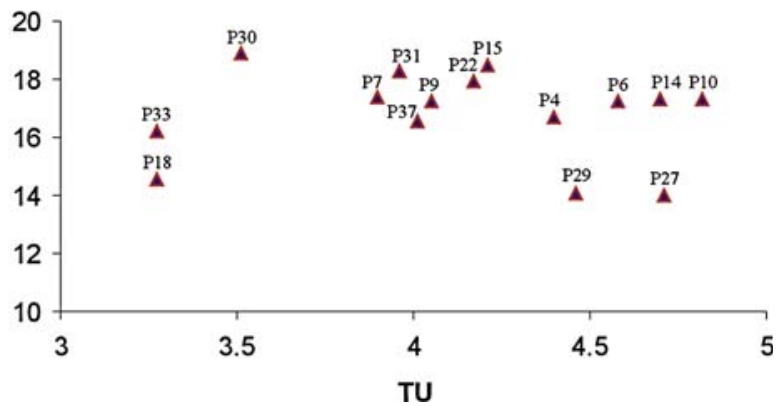

Fig. 6 Relationship between tritium and $\delta^{2} \mathrm{H}$ excess 